\title{
Evaluation of porphyrin $\mathrm{C}$ analogues for photodynamic therapy of cerebral glioma
}

\author{
G Karagianis ${ }^{1,2}$, JS Hill ${ }^{3,4}$, SS Stylli ${ }^{4}$, AH Kaye ${ }^{4}$, NJ Varadaxis ${ }^{5}$, JA Reiss ${ }^{1}$ and DR Phillips ${ }^{2}$ \\ Departments of ${ }^{1}$ Chemistry and ${ }^{2}$ Biochemistry, La Trobe University, Bundoora, Victoria 3083; Departments of ${ }^{3}$ Surgery and \\ ${ }^{4}$ Neurosurgery, Clinical Neuroscience Centre, Royal Melbourne Hospital, University of Melbourne, Melbourne, Victoria 3050; \\ ${ }^{5}$ Department of Natural Sciences, School of Applied Science, Philip Institute of Technology, Bundoora, Victoria 3083, Australia.
}

\begin{abstract}
Summary A series of pure, monomeric porphyrins (2-8) based on porphyrin $C$ (1) have been tested as sensitisers for photodynamic therapy (PDT) of cerebral glioma using the in vitro/in vivo C6 intracerebral animal tumour model. The in vitro screening, consisting of cytotoxicity, phototoxicity (red light) and subcellular localisation studies, revealed two sensitisers (porphyrin 7, molecular weight $863 \mathrm{Da}$ and porphyrin 8, molecular weight $889 \mathrm{Da}$ ), which had greater photoactivity than porphyrin $\mathrm{C}$ and similar photoactivity to haematoporphyrin derivative (HpD) although at a 5-fold higher dose than $\mathrm{HpD}$. Both sensitisers showed intracellular localisation to discrete organelle sites and exhibited considerably less 'dark' cytotoxicity than $\mathrm{HpD}$. The kinetics of uptake of porphyrins $\mathbf{7}$ and $\mathbf{8}$ was studied in the mouse C6 glioma model as well as in biopsy samples from normal brain, liver, spleen and blood. Maximal drug uptake levels in tumour occurred 9 and $6 \mathrm{~h}$ after intraperitoneal injection for $\mathbf{7}$ and $\mathbf{8}$ respectively, at which time the tumour to normal brain ratios were 15:1 and 13:1 respectively. The effect of PDT using porphyrin 7 activated by the gold metal vapour laser tuned to $627.8 \mathrm{~nm}$ was studied in Wistar rats bearing the intracerebral C6 glioma. At a drug dose of $10 \mathrm{mg}$ porphyrin $7 \mathrm{~kg}^{-1}$ body weight and laser doses of up to $400 \mathrm{~J} \mathrm{~cm}^{-2}$ light, selective tumour kill with sparing of normal brain was achieved, with a maximal depth of tumour kill of $1.77 \pm 0.40 \mathrm{~mm}$. Irradiation following a higher drug dose of $75 \mathrm{mg}$ porphyrin $7 \mathrm{~kg}^{-1}$ body weight resulted in a greater depth of tumour kill, but also significantly increased the likelihood and extent of necrosis in normal brain.
\end{abstract}

Keywords: photodynamic therapy; porphyrin C; cerebral glioma

Photodynamic therapy (PDT) is a novel cancer treatment that depends on the retention of a photosensitiser by tumour tissue, followed by treatment of the tumour with laser light of an appropriate wavelength to activate the sensitiser (Gomer, 1989). Haematoporphyrin derivative (HpD) and the more purified fraction Photofrin remain the most widely used photosensitisers for the PDT of solid tumours (Dougherty, 1987), and particularly for cerebral tumours (Kaye and Hill, 1992). However, they both lack a number of properties that have been proposed to be present in an ideal sensitiser (MacRobert et al., 1989). Neither of the substances is composed of a single pure sensitiser, and, despite many laboratory investigations, the definitive active molecular component remains in doubt. In addition, both sensitisers produced prolonged skin photosensitisation.

Porphyrin $\mathrm{C}$ is a sensitiser that has shown tumourlocalising and photosensitising properties both in vitro and in vivo (Liang et al., 1984; Henderson et al., 1985; Scourides et al., 1985, 1986). Recently Kaye (1988) investigated the effectiveness of porphyrin $\mathrm{C}$ as a sensitiser of cerebral glioma because of its potential advantages over $\mathrm{HpD}$, namely the lack of prolonged skin sensitisation and the ability to prepare porphyrin $\mathrm{C}$ as a pure compound. Using a C6 glioma model in rats and mice porphyrin $\mathrm{C}$ was shown by fluorescence analysis to be selectively taken up by the glioma, with only slight fluorescence detected in the brain tissue adjacent to the tumour and no fluorescence in normal brain structures within an intact blood-brain barrier (BBB). Quantitative uptake studies using a ${ }^{35} \mathrm{~S}$-labelled derivative of porphyrin $\mathrm{C}$ showed that maximal uptake into intracerebral tumour occurred $1 \mathrm{~h}$ after intravenous administration, at which time the ratio of sensitiser levels in tumour relative to normal brain was 1000:1 (Kaye, 1988). In PDT studies using Wistar rats bearing the C6 intracerebral glioma, porphyrin $\mathrm{C}$ was found to cause selective tumour kill at doses of up to $100 \mathrm{mg} \mathrm{kg}^{-1}$ and 200

Correspondence: J S Hill, Department of Surgery, Royal Melbourne Hospital, Melbourne, Victoria 3050, Australia

Received 20 July 1995; revised 11 September 1995; accepted 12 September 1995
$\mathrm{J} \mathrm{cm} \mathrm{cm}^{-2} 628 \mathrm{~nm}$ light, with a measured depth of tumour kill of $3.1 \mathrm{~mm}$, as compared with $4.5 \mathrm{~mm}$ for HpD (Kaye, 1988). Kaye also examined the in vitro sensitivity of $\mathrm{C} 6$ glioma cells to photosensitisation with porphyrin $\mathrm{C}$ and found that it was significantly less photoactive than $\mathrm{HpD}$ at equivalent doses and suggested that a 10 -fold increase of porphyrin $\mathrm{C}$ over $\mathrm{HpD}$ was required to achieve the same in vitro cell kill. This difference in photoactivity was proposed to be related to the subcellular localising property of the two porphyrins. HpD localises both within the cytoplasm and in subcellular organelles of glioma cells (Hill et al., 1992a), whereas porphyrin $\mathrm{C}$ remains extracellular, and seems only to loosely associate to the outer cell membrane (Kaye, 1988).

Thus in summary, both the in vitro and in vivo studies on porphyrin $\mathrm{C}$, have shown that it is a less powerful photosensitiser than $\mathrm{HpD}$ at equivalent doses. A photosensitiser of equal purity and similar pharmacokinetics to porphyrin $\mathrm{C}$, but with the tumour sensitising properties of $\mathrm{HpD}$, would be desirable. This paper reports on several analogues of porphyrin $C$ that have been tested as sensitisers for PDT of cerebral glioma using the C6 tumour model.

\section{Materials and methods}

\section{Porphyrins}

Porphyrin C (1, Table I) was synthesised according to the procedure of Scourides et al. (1986), and an adaptation of this protocol was used for the synthesis of the porphyrin $C$ analogues (2-8) as previously described (Karagianis et al., 1993). HpD was supplied by the Queen Elizabeth Hospital, Adelaide, Australia. Before use, a standard solution of each porphyrin was prepared at a concentration of $5 \mathrm{mg} \mathrm{ml}^{-1}$ in isotonic saline. Porphyrin $\mathrm{C}$ and analogues $(2-8)$ had similar absorbance spectra and extinction coefficients to $\mathrm{HpD}$ (Karagianis et al., 1993).

\section{Cells}

The C6 rat glioma cell line was obtained from the American Type Culture Collection (Rockville, MD, USA) and was 
maintained as a monolayer culture in RPMI-1640 medium [Commonwealth Serum Laboratories (CSL), Parkville, Australia] supplemented with $10 \%$ fetal calf serum (FCS) (Gibco, Australia) and $2 \mathrm{~mm} \mathrm{L-glutamine} \mathrm{(CSL).} \mathrm{Standard}$ culture conditions of $37^{\circ} \mathrm{C}$ and $5 \%$ carbon dioxide were used.

\section{Colony survival assay and dark toxicity}

C6 rat glioma cells were grown in $80 \mathrm{~cm}^{2}$ flasks (Nunclon) for 3 days after subculturing. While in the logarithmic phase of growth, the cells were harvested via the removal of the spent medium, washed with $10 \mathrm{ml}$ of phosphate-buffered saline (PBS) (CSL), detached with $3 \mathrm{ml}$ of tryspin-versene (CSL) and then diluted with $7 \mathrm{ml}$ of RPMI- 1640 medium containing $10 \%$ FCS before being centrifuged at $2000 \mathrm{~g}$ for $5 \mathrm{~min}$. The pellet was resuspended in $10 \mathrm{ml}$ of culture medium and the viable cells counted using a haemocytometer and trypan blue exclusion test. Typically, a single cell suspension of 200 viable cells was seeded to $25 \mathrm{~cm}^{2}$ tissue-culture flasks (Nunclon) prewrapped in aluminium foil, and incubated for $6 \mathrm{~h}$ to allow for cellular attachment to the base of the flask. Varying doses of porphyrin photosensitiser $\left(0-100 \mu \mathrm{g} \mathrm{ml}^{-1}\right)$ were added to the appropriate foil-wrapped flasks and the cells incubated for $18 \mathrm{~h}$, washed twice with $2 \mathrm{ml}$ of medium to remove exogenous porphyrin and further incubated for 7 days in $2 \mathrm{ml}$ of fresh medium. Colonies were fixed using triplicate $3 \mathrm{ml}$ aliquots of methanol-glacial acetic acid mixture (7:3, v/ v) over three $15 \mathrm{~min}$ periods, and then stained with $2 \mathrm{ml}$ of crystal violet solution $(1 \%, \mathrm{w} / \mathrm{v})$ over a $1 \mathrm{~h}$ period. Flasks were washed with cold water to remove excess dye and the colonies (greater than 50 cells) scored using a lightbox or inverted microscope. Each experiment was performed in triplicate and duplicated on a different day.

\section{In vitro phototoxicity (red-light)}

C6 cells were harvested and seeded into $25 \mathrm{~cm}^{2}$ flasks as described in the colony survival assay (above). The cells were incubated in the presence of $50 \mu \mathrm{m}$ of porphyrin for $18 \mathrm{~h}$, washed twice with $2 \mathrm{ml}$ of medium and resuspended in $2 \mathrm{ml}$ of fresh medium before exposure to light. The foil was removed, and the flasks placed on a lightbox and exposed to red filtered light from a broad-band fluorescent source (NEC $15 \mathrm{~W}$ standard cool white, Nippon Electrical, Tokyo, Japan). The red-light output was achieved by placing filters between the flasks and the opaque Perspex top of the lightbox. This filter combination (Rosco Supergel No.15 and No.25 filters, Masson Photographics, Bulleen, Australia) allowed transmission only of light above $600 \mathrm{~nm}$, at an energy dose of $0.2 \mathrm{~J} \mathrm{~min}^{-1} \mathrm{~cm}^{-1}$. The cells were exposed to the red filtered light at room temperature for varying times between 0 and 60 min and the flasks then re-wrapped in aluminium foil and incubated for a further 7 days at $37^{\circ} \mathrm{C}$ and $5 \%$ carbon dioxide. Adherent colonies were fixed, stained and scored as described in the colony survival assay. The dose dependence of photoxicity was also investigated for the porphyrin photosensitisers 7 and 8 over the range $0-100 \mu \mathrm{g} \mathrm{ml}^{-1}$. The experimental procedures and conditions were as above except the red-light exposure time was kept constant (i.e. $60 \mathrm{~min}$ ). After 7 days incubation, adherent colonies were fixed, stained and scored as described above.

\section{Fluorescence microscopy}

Typically, $10^{4}$ cells per flask were seeded into foil-wrapped $25 \mathrm{~cm}^{2}$ Nunclon flasks and incubated for at least $6 \mathrm{~h}$ before addition of the porphyrin. All porphyrin solutions were diluted in culture medium to a concentration of $10 \mu \mathrm{g} \mathrm{ml}^{-1}$ before incubation with the cells for either 3 or $24 \mathrm{~h}$. The medium was then removed and the adherent cells washed twice with medium to remove any exogenous porphyrin. The base of the flask was removed with a hot scalpel and a coverslip $(18 \times 15 \mathrm{~mm})$ placed on the culture area to make a wet mount, and the edges of the coverslip sealed with nail polish. The intracellular localised porphyrin was detected using a Biorad MRC 500 confocal laser scanning fluorescent microscope operating at an excitation wavelength of $488 \mathrm{~nm}$ from an argon ion laser, with the emission monitored above $600 \mathrm{~nm}$. Fluorescence images were obtained photographically using Mitsubishi CK 100L film. Control images of C6 cells not incubated with porphyrin showed no detectable fluorescence.

\section{Animals and tumours}

Adult CBA mice, 5-8 weeks old, were injected with $10^{6} \mathrm{C6}$ rat glioma cells using the method developed by Kaye et al. (1986). This procedure resulted in the establishment of discrete xenografted intracerebral C6 tumours. Intracranial implantation of $10^{5}$ C6 glioma cells into adult male Wistar rats weighing between 200 and $300 \mathrm{~g}$ was performed using the method developed by Kaye et al. (1985).

\section{Porphyrin administration in tumour-bearing mice}

A standard solution of the appropriate porphyrin was prepared at a concentration of $5 \mathrm{mg} \mathrm{ml}^{-1}$ in isotonic saline at $\mathrm{pH} \mathrm{7.4,} \mathrm{and} \mathrm{the} \mathrm{solution} \mathrm{sterilised} \mathrm{by} \mathrm{passing} \mathrm{it} \mathrm{through} \mathrm{a}$ $0.2 \mu \mathrm{m}$ millipore filter (Schleicher \& Schull, Germany). Ten days after tumour implantation, CBA mice were injected via the i.p. route with a dose of $75 \mathrm{mg} \mathrm{kg}^{-1}$ body weight of the appropriate porphyrin in a total volume of $0.4 \mathrm{ml}$ of saline, and sacrificed at time points between $2 \mathrm{~h}$ and $24 \mathrm{~h}$ after drug administration. Following sacrifice, the entire brain, liver and spleen were excised from the animal and a blood sample collected $(100 \mu \mathrm{l})$. The brain was sectioned through the tumour and a tissue biopsy sample of normal brain and brain tumour was taken. The porphyrin content of the tissues was then determined using the porphyrin extraction assay described below.

\section{Porphyrin extraction assay}

Uptake of porphyrins into tissue was measured using the method of Kessel and Cheng (1985) as modified by Hill et al. $(1990,1992)$. Typically, a preweighed amount of tissue (20$40 \mathrm{mg}$ ) was suspended in $6 \mathrm{ml}$ of $50 \mathrm{mM}$ Hepes $-10 \mathrm{mM}$ cetyl trimethyl ammonium bromide (CTAB), pH 7.4 and homogenised for $30 \mathrm{~s}$. Triplicate $2 \mathrm{ml}$ aliquots were removed, and each was mixed with $5 \mathrm{ml}$ of a chloroformmethanol mixture $(1: 1, \mathrm{v} / \mathrm{v})$, then thoroughly vortexed and centrifuged at $2000 \mathrm{~g}$ for $5 \mathrm{~min}$. The upper aqueous phase and a layer of cell debris at the interface between upper and lower phases were discarded and then the lower organic phase was collected. All extracted porphyrins were present in the lower phase with no porphyrins detectable in the upper phase by fluorescence measurements. Similarly no porphyrins were detectable in the debris layer after re-extraction. The chloroform lower phase was then evaporated to dryness under a stream of nitrogen gas, and the resulting residue was suspended in $2.5 \mathrm{ml}$ of $50 \mathrm{mM}$ hepes $-10 \mathrm{mM}$ CTAB, pH 7.4. The absorbance of these solutions was then determined at $400 \mathrm{~nm}$ relative to a control blank that determined the level of endogenous porphyrin extracted from unsensitised tissue. Those extracts with higher absorbance values were diluted with $50 \mathrm{mM}$ Hepes $-10 \mathrm{mM}$ CTAB, pH 7.4, such that their final absorbance was equal to 0.15 absorbance units in a $1 \mathrm{~cm}$ path length cell. This dilution step overcame the problem of concentration-dependent quenching of the fluorescence emission by either the extracted porphyrin or haemoglobin that was co-extracted with the porphyrin from the tissue samples. Quantitative fluorescence measurements of the extracted porphyrin were made using an excitation wavelength of $402 \mathrm{~nm}$ and an emission wavelength of $624 \mathrm{~nm}$ in a Perkin Elmer LS 30 spectrofluorimeter equipped with a redsensitive R928 Hamamatsu photomultiplier tube (PerkinElmer, Australia). The total amount of porphyrin in each tissue sample was determined relative to a standard curve of known amounts of porphyrin subjected to the above extraction procedure. 


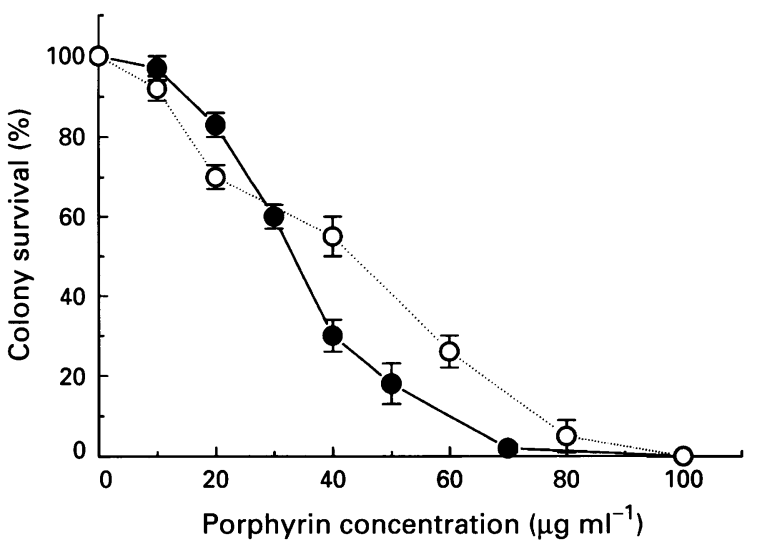

Figure 2 The dose-dependent phototoxicity of C6 rat glioma cells incubated for $18 \mathrm{~h}$ in medium containing porphyrins $7(O)$ or $8(O)$, and then washed in porphyrin-free medium before irradiation with red light for $60 \mathrm{~min}$. Each data point was performed in triplicate, and for each curve values are expressed as the per cent of the number of colonies surviving following a drug dose of $0 \mu \mathrm{g} \mathrm{ml}^{-1}$ and $60 \mathrm{~min}$ light exposure. Bars represent one standard deviation of the mean.

photosensitising C6 cells under red-light conditions. However, C6 cells treated with an equimolar concentration of porphyrins 7 and 8 respectively were killed at a similar rate to HpD-treated cells, although concentrations of these porphyrin $\mathrm{C}$ analogues five times that of $\mathrm{HpD}$ were required to mediate the same degree of cell kill (Figure 1). Exposure to $60 \mathrm{~min}$ of red light resulted in a $78 \%$ reduction in colony survival for porphyrin 7, 54\% for porphyrin 8 and $70 \%$ for $\mathrm{HpD}$ (Figure 1).

Photosensitisers 7 and 8 demonstrated a consistent dosedependent photoactivated toxicity following $60 \mathrm{~min}$ of redlight exposure over the dose range $0-100 \mu \mathrm{g} \mathrm{ml}^{-1}$ (Figure 2). A $50 \%$ reduction in colony survival was observed at $33 \mu \mathrm{g} \mathrm{ml}^{-1}$ for porphyrin 7 and $42 \mu \mathrm{g} \mathrm{ml}^{-1}(47 \mu \mathrm{M})$ for porphyrin 8 , with $100 \%$ lethality at doses exceeding $70 \mu \mathrm{g} \mathrm{ml}^{-1}(81 \mu \mathrm{M})$ for porphyrin 7 and $100 \mu \mathrm{g} \mathrm{ml}^{-1}$ $(112 \mu \mathrm{M})$ for porphyrin 8 .

\section{Subcellular localisation}

The subcellular localisation of the porphyrin thioethers in C6 glioma cells was investigated by confocal laser scanning fluorescence microscopy, a novel microscopic method that has been used for identifying the subcellular localisation of fluorescent porphyrin compounds (Woodburn et al., 1991; Hill et al., 1992a,b). Porphyrin localisation was studied at a concentration of $10 \mu \mathrm{g} \mathrm{ml}^{-1}$ with incubation times of 3 and $24 \mathrm{~h}$ respectively. With the exception of porphyrin $\mathrm{C}(\mathbf{1})$ and $N, N^{\prime}$-diacetyl porphyrin C (2), both of which associated only with the external surface of the cell membrane, all porphyrins localised intracellularly. Following $3 \mathrm{~h}$ incubation, porphyrins 3-7 showed a similar pattern of localisation, in which fluorescence was detected both throughout the cytoplasm and in a distinct punctate pattern, possibly associated with subcellular organelles (Figure 3a). In contrast, porphyrin 8 appeared to be localised exclusively to subcellular organelles. By comparison with the distribution of porphyrins known to localise specifically to mitochondria (Woodburn et al., 1991; Hill et al., 1992a,b), the site of localisation may be mitochondrial (Figure $3 b$ ), although it is possible that the localisation may be in other structures such as lysosomes. After $24 \mathrm{~h}$ incubation the intracellular fluorescence of all porphyrins was most pronounced around the nuclear membrane. There was no porphyrin fluorescence detected in the nucleus during any of these experiments, a finding which was in agreement with previous studies (Woodburn et al., 1991; Hill et al., 1992a,b). a

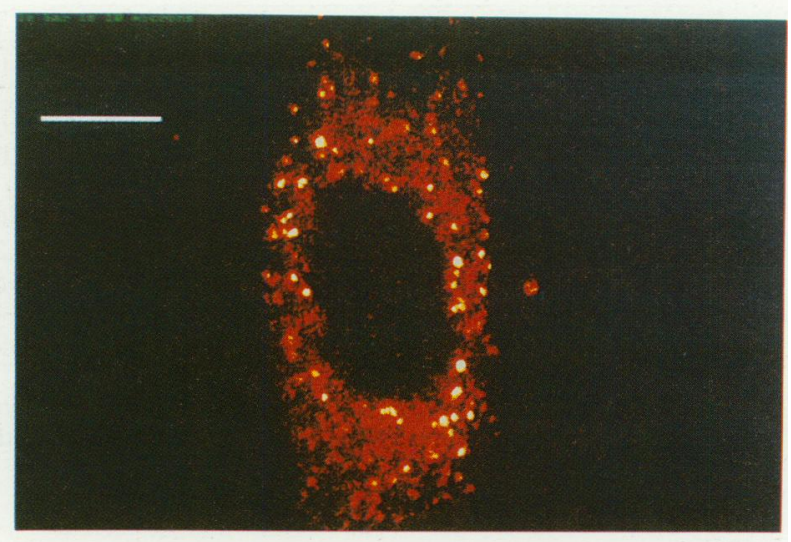

b

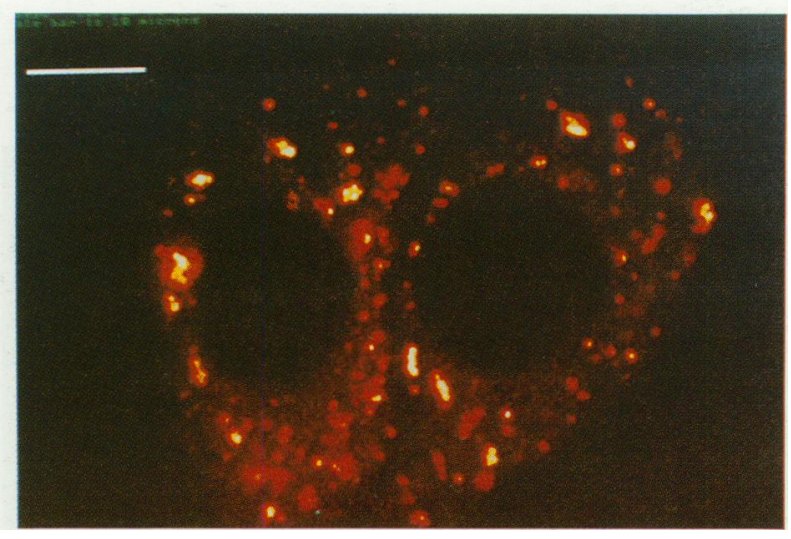

Figure 3 The confocal laser scanning micrograph of $\mathrm{C} 6$ rat glioma cells incubated for $3 \mathrm{~h}$ with porphyrin 7 (a) or porphyrin 8 (b) at a concentration of $10 \mu \mathrm{g} \mathrm{ml}^{-1}$. The scale bar in each panel represents $10 \mu \mathrm{m}$.

\section{Biodistribution and tumour localisation}

Of the porphyrin $\mathrm{C}$ analogues evaluated in vitro, only porphyrins 7 and 8 exhibited significant red-light phototoxicity, and therefore only these were selected for further in vivo uptake studies using the C6 glioma model.

The kinetics of uptake of the photosensitisers 7 and 8 were studied in a mouse model of cerebral glioma to determine the time at which there was the greatest differential between the level of sensitiser in the tumour and in the normal brain. In addition, the distribution of the photosensitisers in various other organs was also examined. The pharmacokinetics of uptake of porphyrins 7 and 8 into tumour and various other organs is summarised in Table II. For porphyrin 7 the uptake into tumour was maximal $9 \mathrm{~h}$ after administration $\left(17.6 \pm 1.3 \mu \mathrm{g} \mathrm{g}^{-1}\right.$ tissue), at which time the level in normal brain in the contralateral hemisphere was $1.2 \pm 0.5 \mu \mathrm{g} \mathrm{g}^{-1}$, representing a tumour to normal brain ratio of approximately 15:1. A photograph taken under Woods lamp exposure demonstrates the localisation of porphyrin 7 in the glioma at the time of maximal uptake (Figure 4a). The photograph shows the discrete localisation of the photosensitiser to intracerebral tumour, with only slight fluorescence in the brain adjacent to tumour and no detectable fluorescence in normal brain. This result compares favourably with an adjacent coronal section of the same brain stained with haematoxylin and eosin that shows demarcation of the tumour from the normal brain (Figure $4 \mathrm{~b}$ ). It is interesting to note that the discrete fluorescence in the upper region of the opposite hemisphere is due to localisation of porphyrin 7 to tumour tissue that has invaded into that hemisphere along 
Table II Uptake studies of porphyrins 7 and 8 administered into C6 tumour-bearing mice at a dose of $75 \mathrm{mg} \mathrm{kg}^{-1}$ body weight, respectively ${ }^{\mathrm{a}}$

\begin{tabular}{lcrrrrr}
\hline Porphyrin & $\begin{array}{c}\text { Time } \\
(h)\end{array}$ & Tumour & Brain & Liver & Spleen & Blood \\
\hline $\mathbf{7}$ & 2 & $5.3 \pm 0.7$ & $2.3 \pm 0.5$ & $52 \pm 11$ & $22.5 \pm 0.9$ & $104 \pm 11$ \\
& 4 & $10.2 \pm 0.7$ & $2.0 \pm 0.4$ & $35.6 \pm 2.4$ & $15.0 \pm 2.8$ & $65.3 \pm 18.4$ \\
& 9 & $17.6 \pm 1.3$ & $1.2 \pm 0.5$ & $25.0 \pm 4.6$ & $8.9 \pm 1.4$ & $34.2 \pm 3.7$ \\
& 15 & $14.5 \pm 1.0$ & $1.6 \pm 0.3$ & $17.6 \pm 1.9$ & $6.6 \pm 0.7$ & $21.3 \pm 6.3$ \\
& 24 & $10.0 \pm 1.2$ & $2.0 \pm 0.2$ & $12.1 \pm 2.2$ & $4.8 \pm 1.8$ & $12.1 \pm 0.7$ \\
$\mathbf{8}$ & & & & & \\
& 3 & $12.6 \pm 1.0$ & $1.6 \pm 0.2$ & $87 \pm 1.2$ & $40 \pm 12$ & $63 \pm 13$ \\
& 6 & $15.6 \pm 1.1$ & $1.2 \pm 0.2$ & $42 \pm 19$ & $18.7 \pm 5.0$ & $39.3 \pm 6.5$ \\
& 9 & $8.6 \pm 0.8$ & $1.5 \pm 0.1$ & $28.6 \pm 1.2$ & $13.3 \pm 1.4$ & $20.1 \pm 8.0$ \\
& 15 & $3.8 \pm 0.7$ & $1.4 \pm 0.7$ & $16.4 \pm 4.1$ & $6.0 \pm 3.1$ & $9.8 \pm 1.7$ \\
\hline
\end{tabular}

${ }^{\text {a }}$ Uptake values (mean \pm s.d.) are expressed as $\mu \mathrm{g}$ porphyrin $\mathrm{g}^{-1}$ tissue wet weight, and for blood as $\mu \mathrm{g}$ porphyrin $\mathrm{ml}^{-1}$ whole blood. The number of animals for each time point was either three or four.

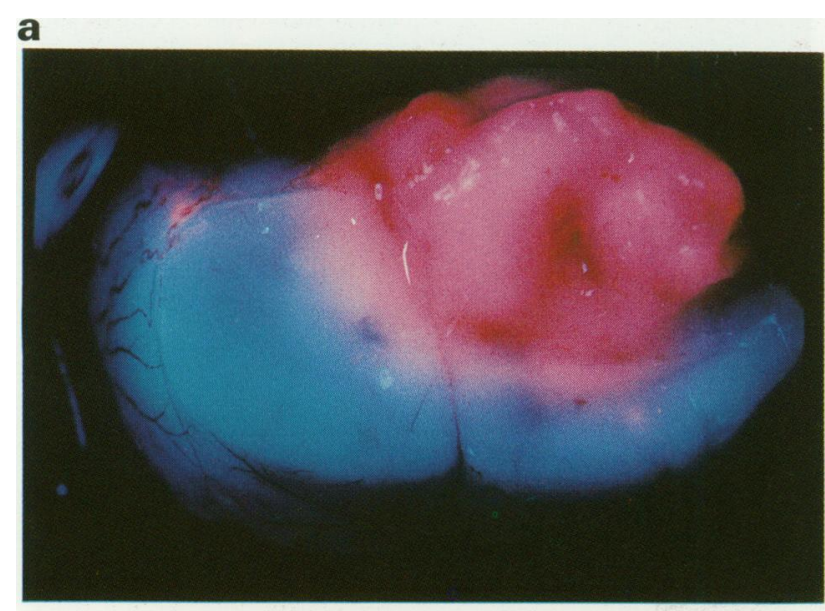

b

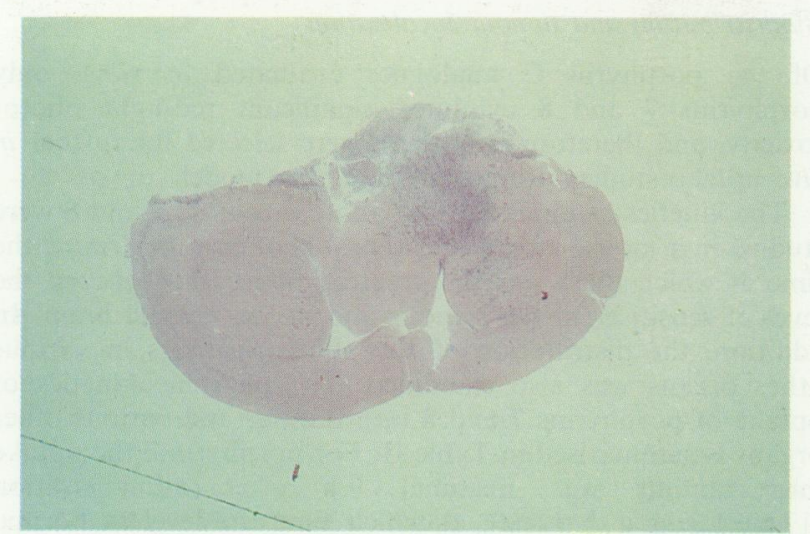

Figure 4 Coronal section of a brain containing implanted tumour from a mouse sensitised via the i.p. route with porphyrin 7 at a dose of $75 \mathrm{mg} \mathrm{kg}^{-1}$ body weight. The same section is photographed under UV light (a) and stained with haematoxylin/ eosin (b).

the subpial plane (Figure 4b). The uptake of porphyrin 7 into other mouse organs shows that the highest levels were observed in the blood, with maximal uptake occurring $2 \mathrm{~h}$ after injection (Table II). The amount of photosensitiser in the blood and liver remained higher than that in the tumour over the $24 \mathrm{~h}$ post-injection period.
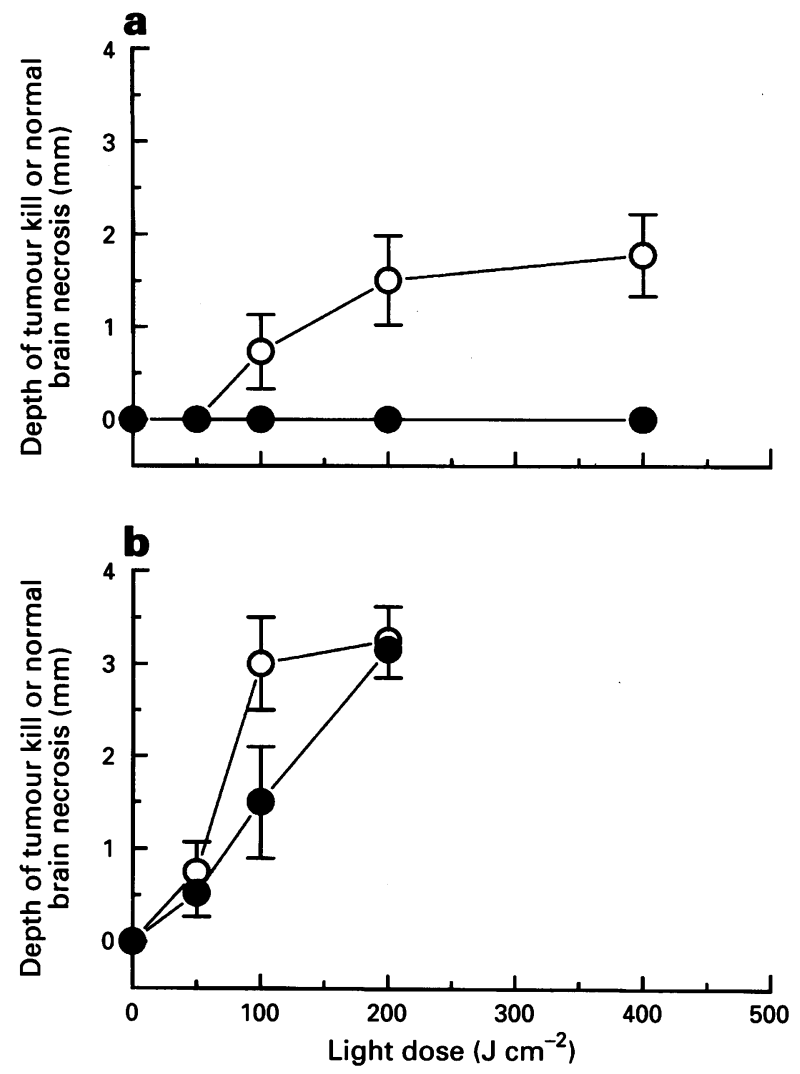

Figure 5 The depth of tumour kill $(O)$ or normal brain necrosis (O) in the Wistar rat C6 glioma model following irradiation with the gold metal vapour laser $9 \mathrm{~h}$ after i.p. administration of porphyrin 7 at doses of $10 \mathrm{mg} \mathrm{kg}^{-1}$ body weight (a) and $75 \mathrm{mg} \mathrm{kg}^{-1}$ body weight (b). The number of animals studied at each data point was either three or four. Bars represent one standard deviation of the mean.

Following administration of porplyrin 8 the uptake into tumour was maximal at $6 \mathrm{~h}\left(15.6 \pm 1.1 \mu \mathrm{g} \mathrm{g}^{-1}\right)$ at which time the level in the surrounding normal brain was $1.2 \pm 0.2 \mu \mathrm{g} \mathrm{g}^{-1}$, representing a tumour to normal brain ratio of approximately 13:1 (Table II). The uptake into other mouse organs shows that the highest levels were observed in the liver in the intial $4 \mathrm{~h}$ post-injection period and the amount in the liver, blood and spleen remained higher than that in the brain tumour over the $24 \mathrm{~h}$ post-injection period. 


\section{$P D T$}

Since porphyrin 7 displayed a higher tumour to normal brain uptake ratio than porphyrin $\mathbf{8}$, it was decided to investigate the effect of PDT using porphyrin 7 on C6 intracerebral tumour in Wistar rats.

PDT of porphyrin 7-sensitised normal and C6 tumourbearing rats was carried out to establish the dosimetry parameters within which PDT using this sensitiser could be undertaken to obtain maximal tumour kill without damage to surrounding normal brain.

\section{Dependence of tumour kill and normal brain necrosis on dosage of photosensitiser and light}

When $10^{5} \mathrm{C} 6$ tumour cells were implanted at a depth of 1.5$2 \mathrm{~mm}$ from the outer bone margin, intracerebral tumours grew to the surface of the brain. The maximal depths of tumour kill as a function of light dose following administration of either 10 or $75 \mathrm{mg}$ porphyrin $7 \mathrm{~kg}^{-1}$ body weight respectively are shown in Figure 5. The major finding was that the depth of tumour kill was dependent on both sensitiser and light dose. There was no tumour kill in sensitised animals that had not received laser treatment, nor in sensitised animals that received $10 \mathrm{mg}$ porphyrin $7 \mathrm{~kg}^{-1}$ and $50 \mathrm{~J} \mathrm{~cm}^{-2}$ red light. The depth of tumour kill was significantly greater for both sensitiser doses following a light irradiation of $100 \mathrm{~J} \mathrm{~cm}^{-2}$ rather than $50 \mathrm{~J} \mathrm{~cm}^{-2}$. However, there was no significantly greater tumour kill at doses of light greater than $100 \mathrm{~J} \mathrm{~cm}^{-2}$ following a dose of either 10 or $75 \mathrm{mg} \mathrm{kg} \mathrm{kg}^{-1}$ (Figure 5). This non-linear relationship may be due to photobleaching of the photosensitiser at the higher light dose (Kaye and Morstyn, 1987). An example of selective tumour kill at doses of $10 \mathrm{mg} \mathrm{kg}^{-1}$ sensitiser and $200 \mathrm{~J} \mathrm{~cm}^{-2}$ red light is shown in Figure 6. To determine whether the tumour kill achieved was selective, the effect of laser light on the normal brain was studied using non-tumour-bearing Wistar rats sensitised with porphyrin 7 .

Porphyrin 7 in doses of either 10 or $75 \mathrm{mg} \mathrm{kg}^{-1}$ body weight, followed $9 \mathrm{~h}$ later by craniotomy, but no laser treatment, resulted in no damage to the normal brain. It has previously been established that irradiation of saline-irrigated unsensitised brain or tumour with laser light at doses up to $1200 \mathrm{~J} \mathrm{~cm}^{-2}$ delivered at power levels ranging from 0.05 to $1.2 \mathrm{~W}$ at the fibre tip produced no significant damage to either tissue as detected by light microscopy (Kaye and Morstyn, 1987).

There was no evidence of brain necrosis or oedema at a sensitiser dose of $10 \mathrm{mg} \mathrm{kg}^{-1}$ and doses of laser light up to $400 \mathrm{~J} \mathrm{~cm}^{-2}$ (Figure 5a). However, at a sensitiser dose of $75 \mathrm{mg} \mathrm{kg}^{-1}$, significant normal brain necrosis occurred at all light doses (Figure 5b).

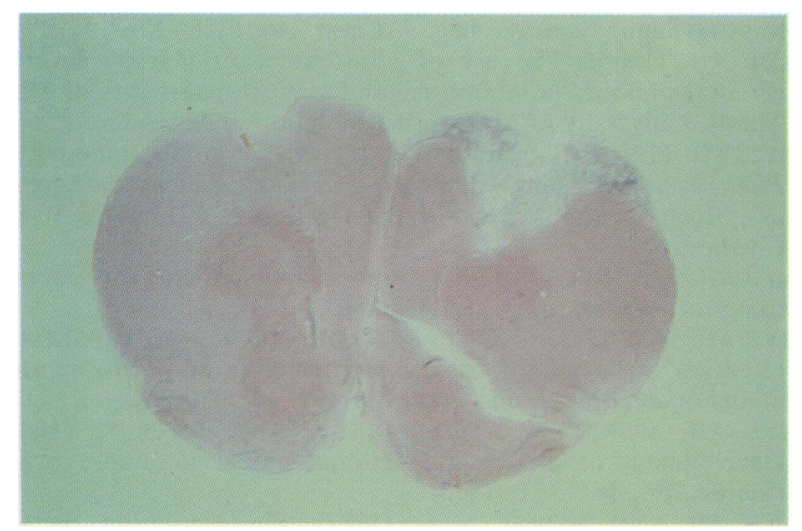

Figure 6 Selective tumour kill in the Wistar rat C6 model after irradiation with $200 \mathrm{~J} \mathrm{~cm}^{-2} 628 \mathrm{~nm}$ light from the gold metal vapour laser $9 \mathrm{~h}$ after administration of porphyrin 7 at a dose of $10 \mathrm{mg} \mathrm{kg}^{-1}$ body weight.
Selective photodynamic kill of cerebral tumours

The data in Figures 5 and 6 show that following doses of $10 \mathrm{mg}$ porphyrin $7 \mathrm{~kg}^{-1}$ and laser doses up to $400 \mathrm{~J} \mathrm{~cm}^{-2}$, selective tumour kill of depth $1.77 \pm 0.40 \mathrm{~mm}$ was achieved without normal tissue necrosis. It is also clear from these results that a dose of $75 \mathrm{mg} \mathrm{kg}^{-1}$ of porphyrin 7 caused a greater depth of tumour kill, but also increased both the likelihood of developing necrosis in the normal brain and the extent of that necrosis.

\section{Discussion}

The in vitro evaluation of the porphyrin $\mathrm{C}$ analogues (2-8) was used as an initial screening in order to select the most promising photosensitisers. The results presented in this study showed that porphyrin $C(1)$ and the analogues $(2-8)$ were considerably less cytotoxic than HpD in the absence of light. Under conditions of red-light exposure, only porphyrins 7 and 8 exhibited substantial photoactivity in comparison with $\mathrm{HpD}$, but required a dose five times higher than $\mathrm{HpD}$ to achieve a similar in vitro cell kill.

Porphyrins 3-8 were shown to localise within C6 cells as detected by fluorescence confocal microscopy, whereas porphyrin C (1) and its $N, N^{\prime}$-diacetyl derivative (2) showed only minimal intracellular uptake. The lack of intracellular incorporation of porphyrins $\mathbf{1}$ and $\mathbf{2}$ is consistent with results obtained in previous studies (Scourides et al., 1985; Kaye, 1988). These porphyrins remain extracellular and associate loosely to the outer cell membrane of tumour cells. This poor cellular uptake is probably due to their extreme hydrophilicity and consequent inability to partition into the hydrophobic environment of the cell membrane. At the shorter incubation time $(3 \mathrm{~h})$, porphyrin 8 localised specifically to subcellular organelles, possibly either mitochondria or lysosomes, whereas porphyrins 3-7 localised generally throughout the cytoplasm and in some regions in a punctate manner. Previous studies have shown similar patterns of intracellular localisation of other porphyrin sensitisers (Woodburn et al., 1991; Hill et al., 1992a,b). This disparity in localisation between porphyrin $\mathbf{8}$ and analogues 3-7 may reflect a difference in the mechanism by which these sensitisers are taken up by the cells, although at present these mechanisms are yet to be precisely described. The localisation of porphyrin photosensitisers in mitochondria may be mediated by the peripheral benzodiazepine receptor located on the outer membrane of the mitochondria, the natural ligands of which are believed to be porphyrins (Verma et al., 1987). A recent structure-localisation study with porphyrins varying in hydrophobicity and charge, suggest that porphyrins that are highly cationic in nature localise in mitochondria, whereas those with a more anionic character tend to localise in lysosomes (Woodburn et al., 1991). However, the possible mitochondrial localisation of porphyrin 8, which is dominantly anionic in character, does not appear to be dependent on the charge of the porphyrin molecule and therefore it can be postulated that other factors, such as hydrophobicity, membrane potential or receptor-mediated uptake mechanisms may be involved. At the longer incubation time $(24 \mathrm{~h})$ there was a distinct change in the intracellular localisation pattern of the porphyrins 3-8, in which fluorescence was most pronounced around the nuclear membrane. This shows that migration or redistribution of the porphyrin molecules to the nuclear membrane may occur with increasing incubation time. Such intracellular redistribution has been reported with other porphyrin photosensitisers (Schneckenburger et al., 1988).

The in vivo evaluation of photosensitisers 7 and 8 in the C6 glioma model has shown that both sensitisers are selectively retained in tumour tissue. This was apparent using Woods lamp exposure to induce fluorescence of the tumour in coronal brain sections, and also by fluorescence assay of the porphyrins extracted from tumour and brain biopsies. Since various studies have shown that photosensi- 
tisers do not cross the $\mathrm{BBB}$, the differential uptake into the tumour as compared with normal tissue is assumed to be, at least in part, due to the disruption of this barrier in the tumour and its maintenance in normal regions of the brain (Rapport, 1976; Yamada et al., 1982; Kaye et al., 1985). However the demonstration of the extremely high tumour to brain ratios that can be achieved using other porphyrin sensitisers (Hill et al., 1992b) suggests that other factors apart from just BBB breakdown must be critical in mediating uptake. Kinetic studies showed that peak drug uptake levels in tumour occurred at 9 and $6 \mathrm{~h}$ after injection for porphyrins 7 and 8 respectively, with maximal tumour to normal brain ratios of $15: 1$ and 13:1 respectively. The uptake of $\mathrm{HpD}$ and porphyrin $\mathrm{C}$ by $\mathrm{C} 6$ intracerebral gliomas has previously been studied by Kaye (1988). HpD showed maximal uptake by fluorescence at $24 \mathrm{~h}$ following i.p. administration and porphyrin $\mathrm{C} 1.5 \mathrm{~h}$ after i.p. injection. Therefore, the rate of uptake of porphyrins 7 and 8 into the tumour is slower than porphyrin $\mathrm{C}$, but faster than $\mathrm{HpD}$. The difference in pharmacokinetics may reflect different mechanisms of vascular transport, uptake and retention for each photosensitiser. Although the sensitisers studied here did not achieve the same ratio between tumour and normal brain as $\mathrm{HpD}$ (30:1; Hill et al., 1990), porphyrin C (1000:1; Kaye, 1989) or a boronated protoporphyrin (400:1; Hill et al., $1992 a, b)$, this is not a great disadvantage if a clear tumourselective PDT response can be generated.

Preliminary PDT studies using porphyrin 7 were encouraging, with selective tumour kill achieved at a dose of $10 \mathrm{mg}$ porphyrin $7 \mathrm{~kg}^{-1}$ and laser doses up to $400 \mathrm{~J} \mathrm{~cm}^{-2}$, resulting in a maximal depth of tumour kill of $1.77 \pm 0.40 \mathrm{~mm}$. At the higher dose of $75 \mathrm{mg}$ porphyrin $7 \mathrm{~kg}^{-1}$, significant normal brain phototoxicity occurred. Phototoxicity to normal brain could result from the presence of sensitiser at sufficient levels in brain to initiate phototoxic reactions. Alternatively, it has previously been reported that the observed depth of damage following PDT is greater than that which could be expected from analysis of the fluence of light, suggesting that damage to vasculature in the irradiated tissue may result in 'downstream' infarction of tissue that is beyond the penetrative depth of the light (Kaye and Hill, 1992). Thus the damage to normal brain in close proximity to the tumour could be a result of the destruction of tumour vasculature causing associated normal tissue death. It is also possible that the accumulation of the products of tumour destruction following PDT may cause congestive oedamatous damage in the adjacent normal tissue.

It has previously been shown that selective kill of cerebral tumours by $\mathrm{HpD}$ using the $\mathrm{C} 6$ glioma model occurs at concentrations of less than $20 \mathrm{mg} \mathrm{HpD} \mathrm{kg} \mathrm{h}^{-1}$ and light doses of less than $200 \mathrm{~J} \mathrm{~cm}^{-2}$ red light (Kaye and Morstyn, 1987). The effectiveness of porphyrin 7 at a concentration of 75 $\mathrm{mg} \mathrm{kg} \mathrm{kg}^{-1}$ and light dose of $400 \mathrm{~J} \mathrm{~cm}^{-2}$, is similar to that obtained with $\mathrm{HpD}$ at $10 \mathrm{mg} \mathrm{kg}^{-1}$ and a light dose of $200 \mathrm{~J} \mathrm{~cm}^{-2}$, for which the mean depth of tumour kill was $4.5 \mathrm{~mm}$ (Kaye and Morstyn, 1987). In contrast, porphyrin C has been shown to mediate tumour kill only at doses greater than $100 \mathrm{mg} \mathrm{kg}^{-1}$ and $200 \mathrm{~J} \mathrm{~cm}^{-2}$ red light, with a mean depth of tumour kill of $3.1 \mathrm{~mm}$ (Kaye, 1988). The preliminary results obtained with porphyrin 7 suggest that further PDT studies at drug doses between 10 and $75 \mathrm{mg} \mathrm{kg}^{-1}$ are required in order to determine the maximum selective dose for this photosensitiser. However, porphyrin 7 does exhibit a greater photodynamic activity than porphyrin $\mathrm{C}$, and a similar activity to $\mathrm{HpD}$ in the $\mathrm{C} 6$ glioma model, although possibly at lower sensitiser doses. Previous uptake studies using $\mathrm{HpD}$ have shown a tumour to brain ratio of 30:1 (Hill et al., 1990; Kaye and Hill, 1992), whereas the ratio reported here for porphyrin 7 was $15: 1$. It is possible that this decreased selectivity may result in lower sensitiser and/or light dose thresholds above which normal brain toxicity will be evident. Future studies may address this question, which has great relevance to increasing an understanding of PDT dosimetry.

In conclusion, the porphyrin 7 photosensitiser may present several advantages over $\mathrm{HpD}$ and Photofrin. It is a pure compound and may, like porphyrin $\mathrm{C}$, have the potential to reduce the side-effects of cutaneous photosensitivity apparent with $\mathrm{HpD}$. In addition, since it is a single chemical species, it would be easier to design derivatives of this compound that may lead to an improvement in efficacy in vivo. Although the maximum selective doses of porphyrin 7 and the subsequent activating light are yet to be determined, preliminary results suggest that it is a compound to be considered for future preclinical PDT studies on cerebral glioma.

\section{Abbreviations}

PDT, photodynamic therapy; $\mathrm{HpD}$, haematoporphyrin derivative; FCS, fetal calf serum; PBS, phosphate-buffered saline; Hepes, hydroxoyethylpiperazine- $N$-2-ethanesulphonic acid; CTAB, cetyltrimethylammonium bromide; i.p., intraperitoneal.

\section{Acknowledgements}

The studies reported in this paper were supported by grants from the NH and MRC (Australia), ACCV (Australia), Stroke Research Foundation and RACS (Australia). One of us (GK) acknowledges the award of a La Trobe University Postgraduate Research Scholarship.

\section{References}

DOUGHERTY TJ. (1987). Photosensitisers: therapy and detection of malignant tumours. Photochem. Photobiol., 45, 879-889.

GOMER CJ. (1989). Photodynamic therapy in the treatment of malignancies. Semin. Haematol., 26, 27-34.

HENDERSON RW, BOHMER RM, KAYE AH, CLEZY PS, GARDNER JM, SCOURIDES PA AND MORSTYN G. (1985). Porphyrin C (Pc): a compound for use in phototherapy of tumours with no significant generalised photosensitivity. In Photodynamic Therapy of Tumours and Other Diseases, Jori G and Perria C. (eds) pp. 263-266. Librero Progretto Publication: Padua.

HILL JS, KAYE AH, SAYWER WH, MORSTYN G, MEGISON PD AND STYLLI S. (1990). Selective uptake of haematoporphyrin derivative into human cerebral glioma. Neurosurgery, 26, 248 254.

HILL JS, KAYE AH, KAHL SB, STYLLI SS, GONZALES MF, WARD AD AND VARDAXIS NJ. (1992a). Uptake of photosensitizers into cerebral glioma. In Photodynamic Therapy and Biomedical Lasers, Spinelli P, Dal Fante M and Marchesini R (eds) pp. 370-374. Elsevier Science Publishers: Amsterdam.

HILL JS, KAHL SB, KAYE AH, STYLLI SS, KOO M-S, GONZALES MF, VARDAXIS NJ AND JOHNSON CI. (1992b). Selective uptake of a boronated porphyrin in an animal model of cerebral glioma. Proc. Natl Acad. Sci. USA, 89, $1785-1789$.
KARAGIANIS G, REISS JA AND SCOURIDES PA. (1993). Preparation and characterisation of porphyrin $\mathrm{C}$ analogues as agents for photodynamic therapy. Aust. J. Chem., 46, 1755-1762.

KAYE AH. (1988). The use of photoradiation therapy to treat cerebral tumours: a laboratory and clinical investigation. M.D. Thesis, University of Melbourne, Melbourne, Australia.

KAYE AH. (1989). Photoradiation therapy of brain tumours. In Photosensitising Compounds: their Chemistry, Biology and Clinical use, Boch $G$ and Harnett $S$ (eds) pp. 209-221. John Wiley: Chichester.

KAYE AH AND HILLS JS. (1992). Photodynamic therapy of cerebral tumours. Neurosurg. Q., 1, 233-258.

KAYE AH, MORSTYN G AND ASCHROFT RG. (1985). Uptake and retention of haematoporphyrin derivative in an in vivo/in vitro model of cerebral glioma. Neurosurgery, 17, 883-890.

KAYE AH, MORSTYN G, GARDNER I AND PYKE K. (1986) Development of a xenograft glioma model in mouse brain. Cancer Res., 46, 1367-1373.

KAYE AH AND MORSTYN G. (1987). Photoradiation therapy causing selective tumour kill in a rat glioma model. Neurosurgery, 20, $408-415$. 
KESSEL D AND CHENG ML. (1985). Biological and biophysical properties of the tumour localising component of haematoporphyrin derivative. Cancer Res., 45, 3053-3057.

LIANG B, ZHANG Z AND YUAN F. (1984). Killing test of porphyrin C on tumours. Dalian Gongxueyuan Xuebao, 23, 128 (Radiation Biochemistry); Chem. Abs., 102, 181627c.

MacROBERT AJ, BOWN SG AND PHILLIPS D. (1989). What are the ideal photo-properties for a sensitizer? In Photosensitizing Compounds: their Chemistry, Biology and Clinical use, Boch G and Harnett S (eds) pp. 4-16. John Wiley: Chichester.

RAPAPORT SI. (1976). Blood-brain Barrier in Physiology and Medicine. Raven Press: New York.

SCHNECKENBURGER H, RUCK A, BARTOS B AND STEINER R. (1988). Intracellular distribution of photosensitising porphyrins measured by video-enhanced fluorescence microscopy. Photochem. Photobiol.B, 2, $355-363$.

SCOURIDES PA, BOHMER RM, HENDERSON RW, FARRAGHER M AND MORSTYN G. (1985). $N, N^{\prime}$-Diacetyl porphyrin C: its purification, 14C labeling and its photosensitising properties. In Photodynamic Therapy of Tumours and Other Diseases, Jori G and Perria C (eds) pp. 9-12. Librero Progretto Publication: Padua.
SCOURIDES PA, MORSTYN G AND NGU M. (1986). An improved synthesis of porphyrin C. J. Chem. Soc. Chem. Commun., 24, 1817.

VERMA A, NYE J AND SNYDER SH. (1987). Porphyrins are endogenous ligands for the mitochondrial (peripheral-type) benzodiazepine receptor. Proc. Natl Acad. Sci. USA, 84, 22562260 .

WOODBURN KW, VARDAXIS NJ, HILL JS, KAYE AH AND PHILLIPS DR. (1991). Subcellular localisation of porphyrins using confocal laser scanning microscopy. Photochem. Photobiol., 54, 725-732.

YAMADA K, USHIO Y, HAYAKAWA T, KATO A, YAMADA N AND MOGAMI H. (1982). Quantitative autoradiographic measurements of blood-brain barrier permeability in the rat glioma model. J. Neurosurg., 57, $394-398$. 